* Ensaio

\title{
Comunicação e Mediações em Saúde: Um olhar a partir do Programa de Pós-Graduação em Informação e Comunicação em Saúde (ICICT/Fiocruz)
}

\section{Inesita Soares Araújo}

PPGICS/ICICT/FIOCRUZ. Professora do Programa de Pós-Graduação em Informação e Comunicação para a Saúde/ICICT/FIOCRUZ.

inesita@icict.fiocruz.br

\section{Valdir Castro Oliveira}

Professor do Programa de Pós-Graduação em Informação e Comunicação para a Saúde/ICICT/FIOCRUZ.

valdirco@yahoo.com.br

DOI: $10.3395 /$ reciis.v6i3.584pt

\section{Resumo}

Este ensaio se propõe a discutir de que maneira o PPGICS - Programa de Pós-Graduação em Comunicação e Informação em Saúde, oferecido pelo ICICT/Fundação Oswaldo Cruz, problematiza, configura e integra em seu escopo o conceito de mediação, particularmente quando associado à comunicação na saúde pública, representada pelo SUS - Sistema Único de Saúde. Após uma introdução à proposta do Programa, discorre sobre as convergências e as divergências da Comunicação com a Saúde no SUS e, desenvolvendo a idéia de mediação como semiose e alteridade, discute conceitos que orientam o entendimento sobre a mediação a partir de diversos autores. Por fim, aborda mais concretamente, o modo pelo qual o Programa busca desenvolver o conceito, trazendo alguns exemplos de sua utilização em projetos de pesquisa e disciplinas ministradas.

Palavras chaves: Mediação, Comunicação, Comunicação e Saúde, SUS, PPGICS,

\section{Introdução}

Nossa proposta de reflexão gira em torno do conceito de mediação na perspectiva das políticas públicas de saúde do SUS - Sistema Único de Saúde - a partir do binômio Comunicação e Saúde, o qual vem se estruturando como resposta às diversas demandas da saúde e de que maneira este conceito tem sido tratado no PPGICS - Programa de Pós-Graduação em Comunicação e Informação para a Saúde do ICICT/FIOCRUZ.

A relevância atribuída ao conceito de mediação está, aqui, relacionada à análise de práticas da comunicação associadas a contextos e intertextos, como forma de entendimento dos espaços intersticiais, superfícies de contato e zonas de fronteira que marcam o campo da saúde.

Partimos do princípio de que o binômio Comunicação/Saúde se apresenta como um caleidoscópio de práticas sociais suscetíveis de diversas leituras teóricas e práticas em que 
sobressaem os intercâmbios discursivos e várias formas de saber e de agir sobre a saúde, o que, de certa maneira, dificulta uma única forma de abordagem. Por causa disto, optamos centralizar o escopo de nossa reflexão na questão da mediação como fator estruturado e estruturante das formas de comunicação e construção de sentidos que permeiam a sociedade e as políticas de promoção da saúde representadas pelo SUS. Justificamos esta escolha por entendermos que este sistema, criado em 1988, trouxe incontáveis desafios teóricos e práticos tanto para o campo da Comunicação quanto para o da Saúde, ao propor a inversão do modelo de saúde na sociedade brasileira para outro cujos princípios filosóficos pressupõem, entre outras coisas, a descentralização da gestão, a participação da sociedade e novas maneiras de lidar com a saúde em termos individuais e coletivos. Entre vários aspectos que podem ser desdobrados desses princípios, julgamos que um dos mais relevantes foi o que implicou na ampliação e na inclusão ativa de diferentes atores sociais e suas respectivas vozes, contrastando fortemente com as políticas de exclusão social de amplos setores e segmentos sociais que, historicamente, marcaram profundamente a sociedade brasileira. Com os princípios da universalidade, igualdade e eqüidade, todos os setores e segmentos sociais passaram a ser considerados de forma integrada e levados em conta no planejamento e na execução das políticas públicas de saúde, gerando expressões que se tornam correntes no jargão das comunidades epistêmicas ligadas às políticas públicas de saúde, como descentralização, inclusão social, participação popular ou controle social, palavras-chaves que servem para nortear o novo paradigma de saúde representado pelo SUS (CARVALHEIRO, 1999).

Neste novo paradigma, emergiram demandas e maneiras de se pensar a informação e a comunicação, como contraponto aos modelos verticais caracterizados pela persuasão e operados por uma fala central que predominou - e ainda predomina - desde o século passado nas políticas públicas brasileiras de saúde. O surgimento do SUS evidenciou a necessidade de analisar e pesquisar modelos e práticas de comunicação mais interativos, participativos e abertos, além de qualificar os agentes do campo da informação e da comunicação de acordo com o novo paradigma da saúde. Neste aspecto, a reflexão sobre estas áreas foi ampliada em termos quantitativos e qualitativos, permitindo e induzindo a criação de formas específicas de pós-graduação voltadas exclusivamente para o atendimento a estas questões, como aconteceu com a área da Informação e Comunicação, que vem adquirindo cada vez mais importância e presença no cenário da saúde pública no país e cuja estruturação progressiva e consolidação obtiveram um avanço extraordinário no ICICT - Instituto de Comunicação e Informação Científica e Tecnológica - unidade da Fundação Oswaldo Cruz. Além da produção de produtos informacionais e comunicacionais, crescentes pesquisas na área, oferta de inúmeros cursos de extensão e de aperfeiçoamento, o ICICT criou desde o início da década de1990, cursos de pósgraduação lato sensu e, em 2009, a pós-graduação stricto sensu, em nível de mestrado e doutorado, para atender as exigências de formação de pesquisadores e docentes no campo da Informação e da Comunicação.

A missão do ICICT é cuidar dos campos da Informação e Comunicação, atribuindo a eles importante papel estruturante nas políticas públicas de saúde a partir do princípio da interdisciplinaridade, como um princípio comum ao ensino e à pesquisa desta instituição. Isto implica o reconhecimento desses elementos como fundamentais para a pesquisa e a inovação, a prestação de serviços, o ensino, o planejamento, a gestão interna e a discussão pública sobre temas de Ciência \& Tecnologia e Saúde, subsidiando os processos de decisão 
compartilhada com a sociedade e o cidadão. Estas questões impõem ao ICICT o desafio de pensar, construir e articular, de forma interdisciplinar, conceitos e práticas de Informação e Comunicação para a saúde sem se restringir a saberes circunscritos e as rígidas divisões de conhecimentos que costumam marcar o campo acadêmico. Neste movimento, a Informação e a Comunicação se tornam instâncias mediadoras e vetores importantes para superar tanto o tradicional recorte disciplinar quanto permitir um olhar mais amplo sobre a saúde.

Depois de mais de uma década buscando esse caminho através do investimento em pesquisas e no ensino em nível de especialização, o ICICT criou o PPGICS - Programa de Pós-Graduação em Comunicação e Informação em Saúde, inscrito na Área de Avaliação Interdisciplinar da CAPES (órgão coordenador e regulador das atividades de ensino pós-graduado no Brasil).

Partindo de um corpo de pesquisadores docentes com percursos, experiências e tradições acadêmicas diferentes, o PPGICS vem avançando nas possibilidades de novas tessituras epistemológicas e metodológicas que, respeitando os pressupostos de cada disciplina, não se prendem elas. Como consequência, produzem-se olhares enriquecidos e múltiplos sobre as realidades estudadas.

Nesse Programa, dois desafios principais nos incitam: a) constituir objetos de pesquisa interdisciplinares, que integrem conjuntos particulares de conhecimentos e busquem responder mais eficazmente às demandas das novas configurações sociais e políticas, locais, nacionais e internacionais no campo da saúde e b) desenvolver métodos interdisciplinares de pesquisa.

Essas questões atravessam e caracterizam uma área de conhecimento que sintetizamos como "contextos, configurações e dinâmicas da informação e da comunicação em saúde", que se desdobra em dois conceitos que conformaram linhas de pesquisa: inovação e mediações, ambos percebidos como transversais aos temas de pesquisa. Aqui trabalharemos mais especificamente sobre a noção de mediações, palavra chave que nos remete basicamente a dois ângulos da mesma temática: a) os processos de produção, circulação e apropriação de informações e dispositivos de comunicação; b) os discursos, os atores, as redes e as políticas públicas do campo da saúde, na especificidade da informação e da comunicação.

Podem ser analisados sob a ótica das mediações, uma vez que delas dependem para sua efetiva constituição, uma ampla gama de trabalhos: desenvolvimento de metodologias e processos de avaliação da informação e da comunicação, dos sistemas e práticas de informação e da comunicação em saúde, análise de usos de sistemas e metodologias, incluindo as tecnologias de informação e comunicação, virtuais ou não, estudos sobre a divulgação científica nesta área etc. Apesar do seu mencionado caráter transversal, o conceito nomeia explicitamente uma das linhas de pesquisa do PPGICS: Informação, Comunicação e Mediações em Saúde. Segundo sua ementa, a linha:

Estuda as relações entre instituições de saúde e a população, em seus processos de produção, circulação e apropriação de informações, discursos e saberes. Dedica-se à discussão conceitual e ao desenvolvimento de metodologias que levem à melhor compreensão da natureza e das características de suas mediações culturais, sociais, institucionais e tecnológicas. Seus projetos priorizam a construção de indicadores e a análise de produtos, processos e sistemas de informação e comunicação, bem como das políticas públicas nesses domínios; a produção e compartilhamento do conhecimento em redes sociais; o estudo das formas discursivas e relações entre mídia e saúde; o acesso, o uso e a 
apropriação de tecnologias de informação e comunicação em saúde. (FUNDAÇÃO OSWALDO CRUZ, 2009)

Como se pode observar, a idéia de mediação está associada aos processos, fluxos, ciclos de produção-circulação-apropriação de sentidos, às redes sociais e ao desenvolvimento metodológico e conceitual. De um modo geral, nos projetos de pesquisa, tem sido mais associada à comunicação no que ela implica em alteridade, fluxos e movimento dos sentidos. São esses aspectos que buscaremos aprofundar nos próximos tópicos.

\section{Comunicação e Políticas Públicas de Saúde - convergências e divergências}

Historicamente, saúde e comunicação estiveram associadas nas políticas públicas desde os começos do século XX. O contexto científico da época apontava a possibilidade de identificar um agente causador para cada doença, além de formas de transmissão e controle, deslocando-se a atenção dos fatores do meio ambiente para o indivíduo. Por este pensamento, os hábitos das pessoas foram considerados como importantes fatores relacionados com a saúde ou a doença. Como afirmam Araújo e Cardoso (2007, p. 24):

É natural que, nesse contexto interpretativo, que ganhou força das décadas seguintes, educação e comunicação - esta pensada ainda como propaganda - formassem o binômio que deveria garantir o sucesso das políticas públicas em saúde, o que se estendeu pelo século XX até, em boa medida, os nossos dias.

$\mathrm{Na}$ década de 70, foram introduzidos os surveys epidemiológicos, que subsidiavam estudos sobre as superstições e conhecimentos sobre formas de transmissão de doenças e de que maneira deveriam ser substituídos por informações racionais derivadas do campo da saúde. 0 inventário dos conhecimentos sobre transmissão de doenças, costumes, identificação de lideranças locais, veículos de comunicação etc. visava garantir a adequada decodificação das mensagens por parte deste tipo de público (PITTA, 1995, p.241). Neste modelo comunicacional não se auscultava o outro, a população como sujeitos de alteridade, em uma clara estratégia de educação bancária, como já enfatizava Paulo Freire nesta época (FREIRE, 1971).

Essa situação se repete quando se trata do uso de meios de comunicação. Estes assumem centralidade crescente na difusão de informações e sentidos sobre a saúde baseando-se em uma matriz significante que, de modo geral, pode ser assim resumida: a) ela reproduz o modelo técnico-instrumental de comunicação, ao considerar que o outro é o ouvinte, o telespectador ou o leitor para o qual direciona seus conteúdos, imagens e formas sem ouvi-los e sem preocupação de entendê-los como sujeitos, a não ser estatisticamente para otimizar a decodificação das mensagens; b) as representações da saúde enfatizam uma lógica linear de causa e efeito baseada em prescrições e nos relatos de avanços científicos e tecnológicos e a auto-responsabilização dos indivíduos e dos grupos sobre a sua saúde; c) o sucesso ou insucesso midiático das mensagens transmitidas é inferido estaticamente por variáveis que não mostram a processualidade do campo da recepção e das diferentes interpretações e usos das mensagens feitos pelos públicos a que se dirigem, além de levar pouco em conta 0 contexto cultural e situacional em que circulam estas mensagens. Quando existem análises de recepção não estatísticas, estas se resumem a se valer, metodologicamente, do estudo de grupos focais para perscrutar com mais profundidade o comportamento do receptor. No entanto, tal metodologia segue a mesma lógica das análises de efeitos, porque não se trata de 
promover a comunicação e sim de saber de que maneira o receptor pode decodificar os sentidos das mensagens emitidas pelos veículos de comunicação.

Este processo designa o que Antônio Fausto Neto chamou de enunciação como completude para designar a matriz instrumental da comunicação centrada no "sujeito falante". Por este modelo, a linguagem se constitui apenas como um instrumento auxiliar para a transmissão de mensagens para um "sujeito receptor". "Nessa perspectiva, a convicção de transmissão da mensagem enquanto um ato de comunicação ficaria restrito a idéia de que toda expressão do dito estaria contida nas fronteiras mesmas onde está aquele que o pronuncia" (FAUSTO NETO, 2008 , p. 121). Com isso o autor entende que a noção de completude é insuficiente para, analiticamente, dar conta da complexidade das práticas discursivas, já que estas são estruturadas em torno de relações entre sujeitos cujos efeitos de sentidos não ocorrem apenas a partir da intencionalidade de um dos pólos da situação de enunciação. Baseado em Émile Benveniste, afirma que a questão das discursividades ocorre em um território de complexidades nos quais os pólos da relação agem, interagem, interpretam e reinterpretam as mensagens postas em circulação (FAUSTO NETO, 2008, p. 125).

Com o advento do SUS, as perspectivas comunicacionais do modelo instrumental de comunicação foram questionadas de forma mais intensiva trazendo novos desafios para se pensar o papel da Informação e da Comunicação para a saúde sugerindo processos "mais abertos, instáveis, interativos, complexos, entrelaçados, táticos, conformando redes por onde transita a cooperação, conflito, visibilidade e invisibilidades onde se situam, social e politicamente, sujeitos". (PITTA, 1995, p. 258).

Muitos estudos ganharam então relevância, ao tentar responder de que maneira diferentes atores sociais se pronunciam, participam, intervêm, debatem ou fazem valer seus direitos e deveres na construção e funcionamento do sistema de saúde que deve ser mais atento às particularidades dos ambientes sociais, culturais e econômicos, tal como previsto constitucionalmente e em vários documentos legais do SUS.

Sendo uma política de saúde inclusiva, o desafio teórico e prático que emergiu desta proposição não foi apenas o de ofertar mensagens educativas às pessoas, grupos e comunidades sobre a saúde e sim o de torná-los mais sujeito da comunicação passando da condição de ouvintes para a de interlocutores, o que não pode ser viabilizado sem o concurso dos campos da Informação e da Comunicação. Isto trouxe a necessidade de se lidar com diferentes formas de participação, expressão cultural e política da sociedade e buscar novas metodologias de intervenção e ação por parte das políticas públicas de saúde.

Neste aspecto, o conceito teórico de mediação ganha relevância, situando-se como importante referência para a linha de pesquisa do PPGICS de Informação, Comunicação e Mediações em Saúde.

\section{A mediação como semiose social e alteridade}

A idéia de mediação na comunicação tem sido tratada por vários autores e a partir de várias perspectivas. Começamos com as reflexões de Jesus Martin-Barbero que entende a mediação como articulação entre as práticas de comunicação, a cultura e o contexto social como fatores e lugares de interpelação, reconhecimento e construção dos imaginários sociais e culturais, em particular, na América Latina. Ele vai defender a tese da hibridização da cultura (mestiçage) 
para interpretar o panorama da diversidade cultural, étnica e social que caracterizam as sociedades dessa região e formular, do ponto de vista epistemológico e metodológico, o conceito de mediação a ser aplicado aos estudos da comunicação, tendo como fonte de influência principal, três correntes teóricas que, direta e indiretamente, trataram desse assunto: a) o pensamento do espanhol Manuel Martín Serrano sobre mediações; b) as idéias do italiano António Gramsci sobre cultura, política, hegemonia e contra-hegemonia e c) os estudos culturais (cultural studies).

Partindo da idéia da hibridização da cultura popular com os sistemas midiáticos que vão influenciar mutuamente a constituição dos imaginários sociais da vida cotidiana na América Latina, Martin-Barbero vê neste processo os fatores que constituem as mediações comunicacionais, inclusive aqueles relacionados ao universo midiático (MARTIN-BARBERO, 1997).

Com isso Martin-Barbero inverte a tendência comum dos estudos de comunicação centrada quase que exclusivamente nos mass media para o das mediações em que a produção, a circulação e a compreensão dos sentidos se colocam transversalmente entre diferentes matrizes culturais e políticas. A imbricação destas questões traz novas maneiras de pensar e analisar a processualidade da comunicação em diferentes instâncias da sociedade, inclusive na da saúde.

A partir das perspectivas de Martin-Barbero buscamos também em outros autores contribuições para entender, teórica e metodologicamente, de que maneira o conceito de mediação pode contribuir para a análise e a compreensão dos sentidos comunicacionais tanto a partir das políticas públicas de saúde representadas pelo SUS quanto pelas relações que estabelecem com diferentes atores sociais e o papel da comunicação midiática nestes processos. Para isso centramos as nossas buscas naqueles autores que consideram, fundamentalmente, os atos de comunicação como fatores de vinculação social, alteridade de sentidos e construção da vida em comum, como sugere Muniz Sodré. Contrariando as correntes de estudos que resumem suas análises aos meios, mensagens e efeitos, este autor nos diz que a comunicação, como processo de mediação, emerge, fundamentalmente, a partir de atos de compartilhamentos de vínculos e de um comum no qual a vida social se manifesta e se reproduz tanto pela via do pensamento racional quanto pela sua dimensão sensível (emoções, afeto, desejos e prazer) que contribuem para produzir a reciprocidade interlocutória e os sentidos das interações sociais. Mas ressalta que nem o vínculo e nem o comum devem ser entendidos como simples aproximação e junção de sujeitos com a finalidade de permitir a compreensão recíproca, mas sim como processo que instaura a relação entre subjetividades da qual emerge diferentes estratégias de aproximação e de diferenciação entre os atores sociais (SODRÉ, 2006, p.10-11).

Mas o termo vínculo assevera Sodré, "não deve ser entendido como um mero estar-juntos, aglomerado físico de individualidades ou comunidade enquanto massa gregária, e sim como condição de possibilidade de uma vinculação compreensiva" da qual emerge o comum, ou seja, "a sintonia sensível das singularidades capaz de produzir uma similitude harmonizadora do diverso" que modula o sentido de partilha de uma comunidade (SODRÉ, 2006, p. 69).

Mas ressalta que estas questões não são configuradas apenas por atos intencionais e racionais de comunicação e sim também por uma partilha do sensível que evoca o território da estesia 
que permite os jogos de vinculação que se formam, principalmente, através das práticas discursivas que, por sua vez, permitem a localização e a afetação dos sujeitos no interior da linguagem. Isto é o que permite a aproximação e a diferenciação entre pessoas, grupos, comunidades e propósitos, assim como a convergência ou a divergência entre diferentes saberes, práticas sociais e formas de disputa de sentidos. Mas Sodré explica que o conceito de estesia (aisthéste) não deve ser entendido como estética e sim como "modo sensível de conhecimento de um objeto" presente em todas as formas de interações sociais ligado à "percepção sensível, irredutível ao saber lógico" (SODRÉ, 2006, p. 45).

Com isso Sodré quer dizer que a vinculação por ele aludida não se faz apenas pela lógica do logos (o conhecimento racional, lógico) como oposto ao phatos (paixão, sentimentos, subjetividade ou a dimensão sensível da comunicação) e que esta oposição dificulta compreender a complexidade e o papel da comunicação na vida social.

Neste mesmo diapasão Boaventura de Souza Santos avalia também que o desenvolvimento da ciência contribuiu para exacerbar esta oposição, principalmente em relação ao senso comum representado pelo conhecimento popular, mítico, poético ou religioso. Segundo este autor a afirmação da ciência como uma forma de conhecimento superior, racional e crítico foi obtida a partir da ruptura com o senso comum por ela combatido e considerado como mera opinião (doxa), forma superficial de conhecimento, conservador e preconceituoso. Para Santos a superioridade do conhecimento científico foi obtida a partir de sua ruptura com o senso comum e que este foi combatido por ser considerado mera opinião, forma superficial de conhecimento, conservadora e preconceituosa, situação esta que perdura até hoje no campo científico com sanções sobre determinadas práticas discursivas que fogem do padrão institucional. No campo da saúde, as práticas "desviantes" do modelo biomédico costumam receber sanções legais e jurídicas sob a rubrica de charlatanismo.

Esta forma de entendimento vai derivar, entre outras consequências, na hierarquização do conhecimento em que as questões relacionadas ao phatos ou ao senso comum vão ser desconsideradas e tratadas de forma secundária ou instrumental pela maioria dos estudos que busca explicar os atos comunicativos apenas por sua expressão racional representados por um emissor que, intencionalmente, transmite mensagens através de um canal para um receptor que as decodifica e as interpreta reduzindo a análise às dimensões racionais que julga existir nestes atos.

Mas nem sempre este tipo de razão é capaz de dar conta da complexidade dos sentidos, principalmente em relação ao afeto que é também uma força comunicativa e constitutiva da vida social. A este respeito, o filósofo André Martins, baseado em Nietzche e Espinosa, nos explica que a tradição filosófica tradicional, com consequências até hoje em várias correntes de conhecimento, sempre viu o afeto e a razão como conceitos dicotômicos, sem atentar para o fato de que são os afetos que nos movem e que nem sempre a razão pode modificá-los, a não ser quando se torna uma razão afetiva. Para este autor o afeto nasce das interações sociais e os sentidos dele derivados é que marcam a razão. Partindo desse pressuposto ele define que "Afeto é a reação inevitável a tudo que nos impressiona, a tudo que nos marca, a tudo com o qual interagimos" (MARTINS, 2011).

Nesta direção Samira Challub (1997) analisa também que o afeto revela uma intensidade pulsional que expressa estado emotivo ou sensação (prazer, dor, piedade, ódio ou 
solidariedade) acerca daquilo que nos impressiona permitindo-nos formar nossos imaginários sobre a vida e as interações sociais. Mas, para além de um simples sentimento emotivo, o afeto deve ser visto, ao lado do logos, como parte da formação de nossas convicções e dos sentidos de nossas ações acerca das coisas que nos cercam. Estas questões podem ser observadas, entre outros exemplos, no futebol, nas festas populares, nos movimentos sociais ou comunitários, em mobilizações políticas, no campo da medicina popular e em outros vínculos sociais que plasmam a linguagem e a vida cotidiana. Isto nos leva a considerar o caráter relacional e interativo dos afetos envolvendo o conhecimento, a consciência e a atitude das pessoas diante dos fatos e acontecimentos do mundo.

Neste aspecto as hipóteses defendidas por Santos a respeito do senso comum podem contribuir para o entendimento das mediações comunicacionais. Para este autor, o senso comum deve ser entendido também como uma maneira prática de reconciliar a consciência social com o que existe e de ajudar nas decisões do cotidiano a partir de uma dupla ruptura. Se a primeira foi a ruptura da ciência com o senso comum, a segunda ruptura seria caracterizada por ele como a reconciliação da ciência com o senso comum em que o sensível teria lugar como parte da construção e da ação do homem sobre o mundo. Mas para que o senso comum possa desenvolver plenamente a sua positividade no interior de uma configuração cognitiva seria necessário que as ciências modernas o levassem em conta como uma forma de conhecimento capaz de também interpretar o mundo. Se isso ocorresse, diz Santos, teríamos um senso comum mais esclarecido e uma ciência mais prudente, uma nova configuração do saber que se aproximaria da pronesis aristotélica, ou seja, como um saber prático que dá sentido e orientação à existência e cria o hábito de decidir bem. (SANTOS, 1989).

Paradoxalmente, nem o senso comum e nem a dimensão sensível da vida são estranhas a diversos campos sociais, como o religioso, o político e o midiático. Tampouco são estranhas a várias disciplinas científicas aplicadas na área de mudanças comportamentais (Psicologia, Comunicação, Publicidade, Propaganda, Administração, Marketing, entre outras). Em ambos os casos, observa-se a forte presença estratégica da emoção e do desejo como fatores de mobilização e agenciamento dos imaginários sociais e comportamentais como tem sido apontado por uma farta e diversificada literatura a este respeito desde o início do século XX até o presente momento. Autores como Gustave Le Bon (A Psicologia das Multidões, de 1895), Serge Tchakhotine (A Mistificação das Massas pela Propaganda Nazista, de 1939), Theodor Adorno e Max Horkheimer ( $A$ Indústria Cultural - O Iluminismo como Mistificação das Massas, 1947); Edgar Morin (a Cultura de Massa no Século XX - O espírito do tempo, de 1962), Guy Debord (A Sociedade do Espetáculo, de 1967) até Zigmut Bauman ( $A$ Modernidade Líqüida, de 2000), entre outros, pesquisaram este tema. Comentá-los fugiria ao escopo deste trabalho e cabe aqui apenas observar que a maioria aponta, analiticamente, para o uso estratégico da comunicação dentro da perspectiva instrumental marcada pela linearidade e busca de sentidos com vistas a fins, conforme apontou Jürgen Habermas (1987) ou na do modelo enunciativo da completude, como assinalou Fausto Neto (2008) e não na perspectiva da mediação comunicacional como alteridade apontada no decorrer deste trabalho.

Considerando a mediação como alteridade, destacamos aqui as reflexões de Eliseo Verón ao defender a hipótese de que a mediação está relacionada com a semiose e que esta não pode ser entendida como um processo estático e sim em sua dinâmica capaz de provocar sucessivas 
transformações nas práticas discursivas cujos significados são continuamente alterados. Para isso ele se baseia no conceito de modo de produção de Marx quando este afirma que a produção é imediatamente consumo, o consumo é imediatamente produção e que cada um é imediatamente o seu oposto. Explica ainda que este processo resulta em um movimento mediador na qual a "produção é mediadora do consumo, cujos materiais cria e sem os quais não existiria este objetivo. Mas o consumo é também mediador da produção, enquanto cria para os produtos o sujeito para o qual eles são produtos" (MARX, 1977, p. 47).

Esta estrutura ternária apontada por Marx é reinterpretada comunicacionalmente por Verón a partir da estrutura ternária do signo (signo, referente e interpretante) criada por Charles Sander Peirce para afirmar que todo processo de semiose (produção social dos sentidos) implica em uma rede infinita de produção de sentidos determinados pelas suas condições de produção, circulação e reconhecimento em um movimento contínuo no qual cada instância produz significados e transformações em outra (VERÓN, 1980).

No caso da comunicação midiática, esse contexto analítico nos permite entender de que maneira os atores sociais se enunciam discursivamente nas mensagens postas em circulação e de como o próprio dispositivo midiático inscreve suas marcas nos discursos por ele mediados. Mas fundamental também é saber de que maneira os discursos são dialeticamente transfigurados no campo da recepção uma vez que esta não é uma instância inerte ou passiva diante das mensagens postas em circulação. Pelo contrário, há ali uma dimensão "entrópica" cujo principal característica é a de transformar o próprio sistema produtivo. Quando a mídia se submete relativamente às condições de compreensão do público, ela adota, também, ainda que parcialmente, seus valores e significados, ainda que a fonte de emissão das mensagens dite as regras do jogo, gerando processos de aceitação, complementação, negação ou oposição dando lugar a um movimento mediador. Este caráter mediador do sistema midiático é o que Verón entende como sendo as condições de circulação, ou seja, como o "nome do conjunto de mecanismos que, fazendo parte do sistema produtivo, define as relações entre 'gramática' de produção e 'gramática' de reconhecimento de um discurso ou um determinado tipo de discurso" (VERÓN, 1980, p. 108).

Por esta razão Eliseo Verón nos diz que as práticas discursivas não devem ser vistas apenas como transmissão de informações, mas como efeitos de sentido entre interlocutores e como parte do funcionamento social geral. Isso reitera as idéias de que a análise sobre as mediações deve levar em conta o lugar dos interlocutores, a situação e o contexto histórico-social porque ninguém diz algo de um lugar da sociedade para outro alguém situado em outro lugar da sociedade sem passar por diferentes situações reguladoras da linguagem. "Não se diz o que se quer, em qualquer situação" (ORLANDI, 1983, p. 76).

Assim podemos dizer que o estudo das mediações comunicacionais pode ser compreendido como uma forma de dar conta do trabalho ideológico que opera na constituição do discurso, das operações e regras que regem o trabalho da produção social da significação e da maneira de como os sujeitos produtores e receptores se colocam socialmente situados inscrevendo suas marcas nos discursos postos em circulação na sociedade (PINTO, 1999; ORLANDI, 1983; VERÓN, 1980).

Estas maneiras de compreender a mediação a partir das diversas e diferentes situações interlocutórias e simbólicas são uma forma de compreender as estratégias discursivas 
simbólicas com as quais os atores sociais interpretam a vida cotidiana e as situações vividas, assim como a localização e a afetação dos sujeitos no interior da linguagem. Nesta ambiência, as estratégias sensíveis são parte dos processos de aproximação e diferenciação entre pessoas, grupos ou comunidades que constituem diferentes saberes e práticas sociais concretizando a produção, circulação, reconhecimento e disputa de sentidos (SODRÉ, 2006).

Mas a mediação, para ser

[...] efetuada e se inscrever na ordem social, precisa de bases materiais, que se consubstanciam em instituições ou formas reguladoras do relacionamento em sociedade. Formas da linguagem, instituições mediadora (família, escola, sindicato, partido etc.) investem-se de valores (orientações e práticas de conduta) e são mobilizadoras da consciência individual e coletiva. Valores e normas institucionalizados legitimam e outorgam sentido social às mediações (SODRÉ, 2002, 21).

Inesita Araújo avança nestas questões de maneira mais concreta ao especificar algumas variáveis fundamentais intrínsecas ao processo de mediação. Para isso a autora, compondo uma matriz analítica de fatores de mediação entre centro e periferia discursivos (ARAUJO, 2002), assinala a existência de fontes, que seriam os espaços simbólicos que organizam e produzem mediações a partir do acervo individual, social e cultural dos indivíduos e grupos sociais, os quais se apresentam como pré-construídos (História, Cultura, Religião etc.); de campos, entendidos como espaços sociodiscursivos de natureza abstrata, que podem ser mais ou menos estruturados (no primeiro caso, Estado, Igreja, Sociedade Civil etc; no segundo, temáticas e práticas sociopolíticas); de instâncias, caracterizadas pelos espaços sociodiscursivos concretos, estruturados formalmente, como as organizações, mas também por princípios não formais de organização, como as famílias; por comunidades discursivas, conceito que designa grupos de pessoas que produzem e fazem circular discursos, que neles se reconhecem (MAINGUENEAU, 1993) e são por eles reconhecidos; e os fatores de mediação, que emanam dos vários contextos analisados e promovem ou dificultam o fluxo dos sujeitos entre o centro e a periferia do poder discursivo.

Os fatores foram identificados em seis diferentes ordens: 1) Motivações e Interesses; 2) Relações (pessoais, grupais, comunitárias; institucionais e organizacionais); 3) Competências; 4) Discursividades (discursos, sistemas de nomeações, paradigmas, teorias e modelos); 5) Dispositivos de comunicação (de enunciação, de produção e circulação, tecnologias); 6) Leis, normas e práticas convencionadas (ARAúJO, 2002).

Para Araújo, a valoração destes fatores está vinculada à noção de capital simbólico (BOURDIEU, 1989), particularmente à sua característica de conferir poder simbólico ao interlocutor, de acordo com sua posse, modificando sua posição na escala de poder entre Centro e Periferia discursivos. Ao promoverem o fluxo dos interlocutores entre os diversos lugares de interlocução e nos diversos contextos, os fatores de mediação co-determinam o equilíbrio de forças ou reiteram a assimetria ou as diferenças de capital simbólico entre diferentes interlocutores. Neste aspecto, o capital simbólico se torna, metodologicamente, um importante princípio teórico que pode contribuir para analisar os processos de mediação, principalmente em torno das condições de produção das práticas discursivas. 
Mas, as mediações devem ser pensadas também a partir das redes midiáticas que são capazes de acelerar e ampliar a produção, circulação e consumo de bens simbólicos e de produzir diferentes significados e sentidos para a vida social e a para a saúde.

Guillermo Orozco Gómez em sua tipologia analítica das mediações na recepção televisiva aponta quatro tipos: a) Individuais - provêm da individualidade: capacidades, história, condicionamentos genéticos e culturais, que se articulam com particularidades como sexo, etnia, origem social ou geográfica; b) Situacionais - modo e circunstâncias em que as pessoas interagem com o meio de comunicação, mas também os vários cenários em que se verificam reapropriações; c) Institucionais - relacionadas com cenários que extrapolam o momento da recepção e atuam sobre a reapropriação dos sentidos. As instituições medeiam a agência do sujeito, através do seu âmbito de significação, que é determinado historicamente por sua natureza institucional, objetivos, origem, desenvolvimento e pressões políticas e econômicas a que estão submetidas; d) Massmediáticas - a própria tecnologia exerce mediação. Os meios, apesar de serem uma instituição e veículo de reprodução de outras mediações institucionais, exercem uma mediação peculiar, que vem da sua propriedade como meios que envolvem determinada tecnologia (OROZCO GÓMEZ, 1997).

A proposta metodológica de Orozco Gómez, interpretando e complementando o conceito de mediação em Martin-Barbero, nos chama a atenção para o fato de que as redes midiáticas, por si só, não são capazes de engendrar significados sobre os sentidos da saúde apenas pelo viés da codificação, oferta de mensagens e disponibilidade técnica dos meios. É necessário perguntar (e pesquisar) pela processualidade das mediações, entendidas como práticas discursivas envolvendo o contexto sociocultural, as especificidades dos dispositivos midiáticos e as condições de reconhecimento dos diferentes grupos sociais, variáveis estas que, em seu conjunto, formam sistemas de respostas, de produção de sentidos e compartilhamento de significados capazes de influir nas redes de conversações sociais. Isto nos leva a considerar, por exemplo, de que maneira as narrativas midiáticas constroem, codificam e fazem circular na contemporaneidade diferentes formas de cartografia e fabulação sobre o mundo e, portanto, sobre a saúde.

Neste aspecto, as pesquisas ou estudos sobre a mídia no campo da saúde não podem se contentar apenas com análises de conteúdo ou voltados para afirmar seu caráter apocalíptico como tem sido enfatizado em muitos estudos na área. Embora haja um poder da mídia exercido de forma hegemônica por um pequeno conglomerado de empresas comerciais e familiares que controlam as formas, o conteúdo e a estética das mensagens postas em circulação na sociedade, a mídia deve ser entendida pluralmente porque, socialmente, assume diferentes formatos, principalmente com o advento da Internet. Também não é possível ignorar os milhares de experiências midiáticas de cunho popular, alternativas que emergem no cenário comunicacional, como as rádios e tevês comunitárias, o celular como mídia, jornais locais e comunitários como fatores de mediação, ao lado da chamada mídia de grande alcance.

Mas, em qualquer das situações comentadas, é certo que as mediações vêm se tornando mais e mais complexas, trazendo novas questões para os pesquisadores, inclusive e fortemente para o campo da saúde. Em termos mais concretos, apontam para a necessidade de analisar e compreender a apropriação (tornar algo próprio, converter em saberes e práticas) e as reapropriações das mensagens em saúde em diferentes contextos de produção, circulação e recepção, seja a partir do pólo institucional e da mídia para a população, ou daquelas que são 
forjadas pelas dinâmicas sociais e culturais relacionadas com a reprodução da vida cotidiana. Significa também analisar e buscar compreender de que maneira são gerados saberes e práticas discursivas a partir dos imaginários sociais e populares que, diariamente, dão respostas a um universo infinito de problemas relacionados com a saúde e a doença cujas práticas são derivadas tanto da tradição cultural (benzedeiras, medicina popular, curandeiros espirituais, entre outros) como resposta aos problemas cotidianos ou às carências e dificuldades do sistema oficial de saúde.

O conceito de mediação, tal como viemos tratando até aqui, ajudam a compreender essas situações e as decorrentes formas de conhecimento, incompreensões e dissonâncias cognitivas políticas e simbólicas que, por sua vez, resultam em diferentes imaginários, convicções, crenças e comportamentos que afetam de modo distinto a maneira como as pessoas constituem seu entendimento e seus modos de enfrentamento dos agravos da saúde. Por outro lado, favorece o movimento de desnaturalização de certas formas de comunicação instrumental que obstruem o entendimento da comunicação como processualidade derivada de contextos culturais, políticos e simbólicos na perspectiva da alteridade e da semiose como apresentamos anteriormente.

\section{O conceito de mediação no PPGICS: presença e configuração}

O PPGICS vem atuando com diferentes linhas de pesquisa, projetos e disciplinas, em algumas destas destacando o conceito de mediação, na perspectiva de entender sua configuração nos processos de produção, circulação e apropriação de informações, discursos e saberes. No âmbito reduzido de um artigo, seria difícil contemplar todas as possibilidades exploradas neste sentido, por isto optamos por privilegiar alguns exemplos, frisando, porém, que eles não esgotam os caminhos que vêm sendo trilhados, assim como as abordagens teóricas aportadas anteriormente não representam a totalidade de enfoques adotados pelo seu corpo docente.

\subsection{Disciplinas}

A disciplina Saúde, Mídia e Mediações faz a análise crítica dos meios de comunicação em relação ao seu papel e importância para a configuração e a construção de sentidos sobre a saúde na esfera pública contemporânea. O conceito de mediação é estudado com base na literatura corrente e a partir de exemplos práticos envolvendo políticas públicas de saúde, diferentes textos e contextos midiáticos e diferentes interlocuções da sociedade com o campo da saúde e da comunicação. O aluno é instigado a problematizar a comunicação mais na perspectiva da mediação do que da forma de transmissão de conteúdos.

A disciplina Informação, Conhecimento e Redes Sociais na Saúde reúne um elenco de conceitos para fundamentar os estudos e a reflexão crítica dos alunos a respeito da produção, da comunicação e da apropriação da informação em saúde nos espaços comunitários. 0 conceito de redes sociais é estudado para configurar os elos e as mediações entre os atores sociais em diferentes planos: o cultural, o cognitivo, o simbólico, o técnico. As principais fontes teóricas para o estudo das mediações são os estudos culturais de linhagem inglesa e suas vertentes latino-americanas, além das ciências da informação e da comunicação de origem francesa. A operacionalidade do conceito de mediação é enfatizada tanto para refletir sobre as diferentes dimensões dos processos infocomunicacionais em saúde, quanto para relativizar a dicotomia entre os pólos de emissão e recepção de informações. 
A disciplina Portfolio objetiva ela mesma ser um elemento de mediação entre os alunos, seus percursos acadêmico-científicos e as linhas de pesquisa. Assim, se dá concretude ao entendimento de que a mediação não se destaca dos pólos de produção da comunicação, sendo deles constitutiva e constituinte. Os alunos apresentam e problematizam, em sala de aula e sistematicamente, durante todo o curso, seus achados e posicionamentos, através de um portfolio físico, um virtual e um texto não acadêmico, pelo qual comunica aos participantes seu modo de caminhar, englobando os componentes intelectuais e existenciais. O portfolio permite dar materialidade aos tipos de mediação da ordem das motivações e interesses, relações, competências, discursividades, dispositivos de comunicação e normatividades. (ARAUJO, 2002)

A disciplina Introdução à Teoria e Metodologia da Análise de Discurso adota a perspectiva dos autores da produção social dos sentidos de que os discursos não apenas traduzem visões da realidade, mas formam as realidades, operando em decorrência com a categoria de prática discursiva. Mediação passa a ser, neste contexto, atributo dos discursos, aquele que permite a conversão de uma realidade em outra. Através da análise de textos em diferentes suportes e linguagens (matérias de jornais, vídeos, cartazes, games, programas televisivos entre outros), os alunos vão percebendo a dinamicidade da semiose social e compreendendo o papel mediador dos elementos contextuais, em suas distintas ordens e especificidades.

\subsection{Pesquisas docentes}

Observatório Saúde na Mídia (OSM) é um projeto que abriga iniciativas relacionadas com a construção midiática dos sentidos da saúde. O OSM parte do princípio que a linguagem é uma das primeiras e principais mediações entre os fatos e sua construção semiológica, portanto elemento central na construção das realidades, derivando daí sua forte implicação nas relações de poder. Sobretudo nas de poder simbólico, levando-se em conta a advertência de Bourdieu (1989) de que toda relação de comunicação é uma relação de força e poder. Imagens, textos e diagramação são, em geral, analisados em seu conjunto, tendo em conta a presença de fortes elementos mediadores entre um e outro. A Análise Social de Discursos, pelo seu entendimento dessas questões, tem sido sua principal opção metodológica.

A pesquisa Cartografia de Fontes e Fluxos da Comunicação estabelece a mediação como um dos conceitos centrais, ao lado de poder simbólico e contexto, para entender os demais que estruturam sua proposta metodológica, como comunidades discursivas, mercado simbólico e interdiscursividade. Neste sentido tem caráter metodológico, operando como eixo analítico. A pesquisa objetiva mapear comunidades discursivas que disputam o mesmo mercado simbólico em relação a determinados tema e segmento populacional.

A pesquisa Antropologia da Informação e Redes Sociais na Saúde objetiva realizar uma sistematização do campo teórico-conceitual e empírico-metodológico da linha de estudos da antropologia da informação, recuperando, aprofundando e sistematizando sua trajetória de diálogo com o campo da educação popular e saúde, por meio de dois eixos conceituais: redes sociais e mediações em saúde. Estuda-se a Rede de Educação Popular e Saúde como uma rede de conhecimentos e informações associada à ação social e de que forma emprega diferentes formas de mediações virtuais e presenciais, para sustentar suas ações de mobilização e de luta nos campos acadêmicos, gerencial, político e social da saúde. 


\subsection{Pesquisas discentes}

Os projetos dos alunos da linha de pesquisa em mediação e saúde, mestrado e doutorado, em seu conjunto abordam uma grande pluralidade de práticas sociais na saúde, sendo, porém, comum à maioria deles o entendimento das mediações como estruturantes e estruturadas por seus objetos tanto teóricos quanto empíricos.

A análise desses projetos nos leva a identificar uma forte presença da noção de mediação como dimensão inseparável dos processos semiológicos e das questões que envolvem a relação com o outro. Assim, estudando conselhos de saúde, práticas comunicacionais na internet, processos identitários e deliberativos, redes de compartilhamento, produção de sentidos no ensino a distância, comunicação nos movimentos sociais, nestes e em qualquer outro tema, as mediações estão presentes, seja como prática, como elemento nas relações de poder, como determinante ou resultante de processos intersticiais, de articulação tensa ou sinérgica. Motivações, relações, taxonomias, modelos e paradigmas, conversações, lugares de fala, contextos normativos e consuetudinários, discursos, tecnologias, realidade virtual etc. caracterizam a abordagem do tema das mediações, muitas vezes identificadas como multimediações, segundo proposta de Orozco Gómez (1997) que relata um movimento multidimensional e multidirecional, um processo combinatório de elementos de mediação que determinam o resultado em termos dos sentidos produzidos.

Três exemplos podem dar mais concretude ao modo como a pesquisa discente vem enfrentando o tema das mediações. Uma pesquisa estudou a rede de mediações (recepção e compartilhamento) que se estabelece a partir dos programas do Globo Repórter (Rede Globo de Televisão), particularmente os focados no tema da promoção da saúde e suas relações com a abordagem conferida ao mesmo pelos discursos do Sistema Único de Saúde, identificando estabelecimento de vínculos e pontos de divergência. O principal eixo teórico que permitiu cumprir os objetivos foi o da produção social dos discursos, particularmente a abordagem de uma teoria social dos discursos. As redes de mediações foram traduzidas em Mapas do Mercado Simbólico (fontes e fluxos da comunicação recebida) e Mapas das Redes de Compartilhamento dos sentidos com grupos de pessoas nas cidades do Rio de Janeiro - RJ e Aracaju - SE.

O segundo exemplo trata da pesquisa discente que estudou as representações e os sentidos do silêncio e do silenciamento nas experiências de adoecimento de mulheres vivendo com HIV e aids, lançando luz à idéia de que o silêncio é também uma forma de mediação, no que ele implica em expressão de sentidos e não mudez. Nessa perspectiva, a pesquisa buscou responder: o que é incomunicado por mulheres que vivem com HIV e aids e quais os sentidos produzidos por essa incomunicação? A hipótese que presidiu este trabalho foi a de que o cenário da aids em mulheres é permeado por silêncios relacionados com as implicações da estigmatização presentes no centro da vulnerabilidade social feminina ao HIV/aids. Porém, não obstante essa realidade, as mulheres buscam espaços alternativos em que possam se manifestar e se solidarizarem com pessoas em situações semelhantes, como formas de mediação.

Outro exemplo foi à pesquisa sobre a cobertura jornalística sobre a epidemia de influenza H1N1 pelos jornais O Globo, Extra e Expresso, no período de 25 de abril a 18 de agosto de 2009. O estudo abrangeu a cobertura jornalística desde as primeiras suspeitas de 
contaminação, a confirmação dos primeiros casos, o anúncio de pandemia, a primeira morte no Brasil, a primeira morte no Rio de Janeiro e o início do declínio dos casos de contaminação. O trabalho consistiu na análise da produção discursiva dos jornais em questão mostrando de que maneira a mídia codificou, discutiu e apontou em suas páginas diversos sentidos sobre a epidemia, mostrando de que maneira os acontecimentos e a agenda pública foram construídos e ofertados ao público. Os referenciais teóricos deste estudo foram baseados em Pinto, Fairclough, Bakhtin, e Verón, entre outros, para compreender como as diversas vozes presentes no noticiário se articularam e quais estratégias enunciativas foram utilizadas pelos veículos para dar sentidos à epidemia naquele momento.

\section{Conclusão}

O PPGICS, como uma iniciativa pioneira que reúne os campos da Informação, da Comunicação e da Saúde articulados aos da Ciência e Tecnologia e ao das Políticas Públicas, é um programa que busca compreender a constituição dessas interfaces e ao mesmo tempo se propõe a responder às fortes demandas de formação aí produzidas.

Neste contexto de interdisciplinaridade, avulta-se para a linha de pesquisa de mediações em saúde do Programa o desafio de entender as mediações como espaços transversais e intersticiais de diferentes saberes, da informação e comunicação e de superar modelos e paradigmas da saúde e da ciência e tecnologia que privilegiam exclusivamente a dimensão instrumental da Informação e da Comunicação em Saúde, em detrimento da sua dimensão estruturante das práticas e das relações sociais e institucionais, e seu papel na configuração das relações de poder.

Não é um desafio trivial, seja pela imaterialidade dos processos mediadores, que requerem metodologias adequadas para sua identificação, compreensão e evidenciação, seja pela amplitude e variedade dos enfoques que se apresentam a partir de vários centros de pesquisa do mundo, seja pela multiplicidade de objetos empíricos e teóricos que se apresentam a um Programa interdisciplinar, seja pela provocação que emerge das práticas relacionais do mundo virtual, que problematiza este e outros conceitos.

A impossibilidade de incluir neste artigo todas as correntes teóricas já conhecidas, inclusive algumas que orientam trabalhos do próprio PPGICS, nos levou a privilegiar algumas delas, centrando esforços na sua relação com os conceitos de alteridade e de semiose social. Partimos do binômio comunicação e saúde, lá, no seu ponto de origem, o SUS e a ele retornamos, em sua prática de ensino. São múltiplos processos, múltiplas dimensões e articulações, múltiplas vozes, múltiplas mediações.

\section{Referências bibliográficas}

ARAÚJO, Inesita S. Entre o centro e a periferia: contextos, mediações e produção de sentidos. In: Colóquio Mediações e Usos de Saberes e da Informação: um diálogo França-Brasil, 1., 2008, Rio de Janeiro. Anais... Rio de Janeiro: Icict/Fiocruz, 2008. p.151-165.

- Mercado simbólico: interlocução, luta, poder: um modelo de comunicação para políticas públicas. 2002. Tese (Doutorado) - Universidade Federal do Rio de Janeiro, 2002.

; CARDOSO, Janine M. Comunicação e Saúde. Rio de Janeiro: Ed. Fiocruz, 2007. 
BOURDIEU, Pierre. O poder simbólico. Lisboa: Difel, 1989.

A Economia das trocas simbólicas. São Paulo, Editora Perspectiva, 1982.

CARVALHEIRO, José. R. Os desafios para a saúde. Revista de Estudos Avançados da USP,São Paulo. v.13, n.35, p. 7-20, jan./abr. 1999.

CHALOUB, Samira. Semiótica dos afetos: roteiro de leitura para Um Copo de Cólera, de Raduan Nassar. São Paulo: Hacker Editores, 1997.

FAUSTO NETO, Antônio. Mudança na medusa? A enunciação midiatizada e sua incompletude. In: et al. (Org.) Midiatização e processos sociais na América Latina. (Org.). São Paulo: Paulus, 2008. p. 119-144.

FREIRE, Paulo. Extensão ou comunicação. Rio de Janeiro: Paz e Terra, 1971.

FUNDAÇÃO OSWALDO CRUZ. Instituto de Comunicação e Informação Científica e Tecnológica em Saúde. Programa de Pós-graduação em Informação e Comunicação em Saúde. Documento-base do Programa de Pós-graduação em Informação e Comunicação em Saúde. Rio de Janeiro, 2009.

HABERMAS, Jurgen. La teoria de la ación comunicativa. Barcelona: Taurus, 1987.

MAIngueneaU, Dominique. Novas tendências em Análise do Discurso. Campinas: Pontes/Unicamp, 1993.

MARTIN-BARBERO, Jesus. Dos meios às mediações: comunicação, cultura e hegemonia. Rio de Janeiro: Ed. UFRJ, 1997.

MARTINS, André. Com os pés na vida real. Entrevista. Revista Filosofia. v. 4, n.57, mar. 2011. Disponível em: <http://filosofiacienciaevida.uol.com.br/ESFI/Edicoes/57/artigo2134691.asp>. Acesso em: 24 maio 2012.

MARX, Karl. Introducción general a la crítica de la economia política (1857). 11. ed. México, DF: Pasado y Presente, 1977.

ORLANDI, Eni Pulcinelli. A linguagem e seu funcionamento: as formas do discurso. São Paulo: Brasiliense, 1983.

OROZCO GÓMEZ, Guillermo. La investigación en comunicación desde la perspectiva cualitativa. Guadalajara: IMDEC, 1997.

PINTO, Milton. Comunicação e discurso. São Paulo: Hacker Editores, 1999.

PITTA, A. M. R. Interrogando os campos da saúde e da comunicação. In: Pitta, A. M. R. (Org.) Saúde e Comunicação: visibilidades e silêncios. Rio de Janeiro: Hucitec/Abrasco, 1995.

SANTOS, Boaventura S. Introdução a uma ciência pós-moderna. Rio de Janeiro: Editora Grall, 1989.

SIGNATES, Luiz. Estudo sobre o conceito de mediação. Revista Novos Olhares. CTR-ECAUSP, São Paulo. v.1, n.2, 1998. 
SODRÈ, Muniz. Antropológica do Espelho: uma teoria da comunicação linear e em rede. Petrópolis: Vozes, 2002.

SODRÉ, Muniz. As estratégias sensíveis: Afeto, mídia e política. Petrópolis: Vozes, 2006.

VERÓN, Eliseo. A produção de sentidos. São Paulo: Editora Cultrix, 1980.

Recebido em: 23/04/2012

Aceito em: 21/09/2012 